\title{
Organochlorine Pesticides in Consumer Fish and Mollusks of Liaoning Province, China: Distribution and Human Exposure Implications
}

\author{
Zheng Liu $\cdot$ Hongmei Zhang $\cdot$ Minhui Tao $\cdot$ \\ Shaobin Yang $\cdot$ Liwei Wang • Ying Liu • \\ Dandan Ma $\cdot$ Zhiming He
}

Received: 11 November 2009/ Accepted: 9 March 2010/Published online: 30 March 2010

(C) The Author(s) 2010. This article is published with open access at Springerlink.com

\begin{abstract}
Fish and mollusk samples were collected from markets located in 12 cities in Liaoning province, China, during August and September 2007, and 22 organochlorine pesticides (OCPs) were detected. DDT, $\mathrm{HCH}$, endosulfan, chlordane, and HCB were the dominating OCPs, with mean concentrations and ranges of, respectively, 15.41 and 0.57 to $177.56 \mathrm{ng} / \mathrm{g}, 0.84$ and below detection limit (BDL) to $22.99 \mathrm{ng} / \mathrm{g}, 1.31$ and BDL to $13.1 \mathrm{ng} / \mathrm{g}, 1.05$ and BDL to $15.68 \mathrm{ng} / \mathrm{g}$, and 0.63 and BDL to $9.21 \mathrm{ng} / \mathrm{g}$ in all fish and mollusk samples. The concentrations of other OCPs generally were low and were detectable in a minority of samples, reflecting the low levels of these OCPs in the study region. In general, OCP concentrations were obviously higher in fish than in mollusks, and higher in freshwater fish than in marine fish, which indicated, first, that freshwater fish are more easily influenced than seawater fish and mollusks by OCP residues in agricultural areas and, second, that there are different biota accumulation factors for OCPs between fish and mollusk. To learn the consumption of fish and mollusk, 256 questionnaires were sent to families in 12 cities of Liaoning province. Using the contamination data, average estimated daily intakes of OCPs via fish and mollusk consumption were calculated, which were used for exposure assessment. The public health risks caused by exposure to OCPs in the course of fish and mollusk consumption were compared to noncancer benchmarks and cancer benchmarks.
\end{abstract}

Z. Liu $(\bowtie) \cdot$ H. Zhang $\cdot$ M. Tao · S. Yang · L. Wang ·

Y. Liu $\cdot$ D. Ma $\cdot$ Z. He

College of Science, Liaoning Technical University,

Fuxin, Liaoning Province, China

e-mail: zhengliu_paper@yahoo.com.cn
Persistent organic contaminants (POCs) are among the agrochemicals and technochemistry that have been used extensively for decades in China. These compounds include organochlorine pesticides (OCPs), PCBs, PBDEs, and PCDDs. Since the 1950s, many such substances have been brought into use in large quantities in China, such as DDT and $\mathrm{HCH}$; consequently, pollutant discharge to the environment has grown rapidly and caused undesirable side effects. The environmental behavior of OCPs and PCBs has been investigated for many years. As early as 1962, Rachel Carson's Silent Spring concluded that DDT and other pesticides, designated OCPs today, had insidious effects, harmed birds and other animals and had contaminated the entire world food supply.

Food consumption represents an important pathway for exposure to contaminants from a variety of sources, including pesticide application and industrial processing. Recent studies have indicated that exposures to contaminants in food may pose a public health risk (NRC 1993; MacIntosh et al. 1996). For example, MacIntosh et al. (1996) found that some portion of the adult population may be exposed to individual contaminants in food at concentrations above thresholds of concern. Reports from the U.S. National Research Council of the National Academy of Sciences (NRC) and the Environmental Working Group have also found that pesticide exposures to children could be high enough to cause immediate adverse health outcomes (NRC 1993; Wiles et al. 1998).

Assessments of risks to human health have been undertaken worldwide to examine the potential health risk due to exposure to toxic contaminants in various environmental media and foodstuff (NRC 1993). Large-scale farming and increasing market demand for seafood products should focus more attention on the health consequences via seafood consumption, because historical 
discharge and possible new sources of OCPs are likely to impact adversely the quality of seafood products. This study comprehensively investigates OCP contamination in fish and mollusks in Liaoning province, China. The data enabled us to assess risks related to consumption of the target fish and mollusk products. The goal of this work is to provide baseline information on levels of OCP residues in fish and mollusks in the study area and estimated dietary exposures to certain pesticides through selected food samples that are representative of the diet of the people in the study area.

\section{Methodology}

\section{Sample Collection}

Fish and mollusk samples were collected from markets in 12 cities in Liaoning province, northeastern China, during August and September 2007; the locations of sampling sites are shown in Fig. 1. For fish samples, a clean and acetone-rinsed bistoury was used to take off haslets and muscle, which were then packed in a solvent-rinsed glass bottle with a Teflon-lined cap; for mollusk samples, edible parts of shells were cut off with an acetone-rinsed bistoury and packed in a solvent-rinsed glass bottle with a Teflonlined cap. All samples were stored at $-20^{\circ} \mathrm{C}$ until required for extraction.

A total of 259 fish (111 marine fish and 148 freshwater fish) and 444 mollusk individuals were collected; sample species included three marine fish [hairtail (Trichiurus haumela), small yellow croaker (Psendosciaena polyactis), and Spanish mackerel (Scomberomorus niphonius)], four freshwater fish [bighead carp (Aristichthys nobilis), common carp (Cyprinus carpio), silver carp (hypophthalmichthys molitrix), and crucian carp (Carassius auratus)], and

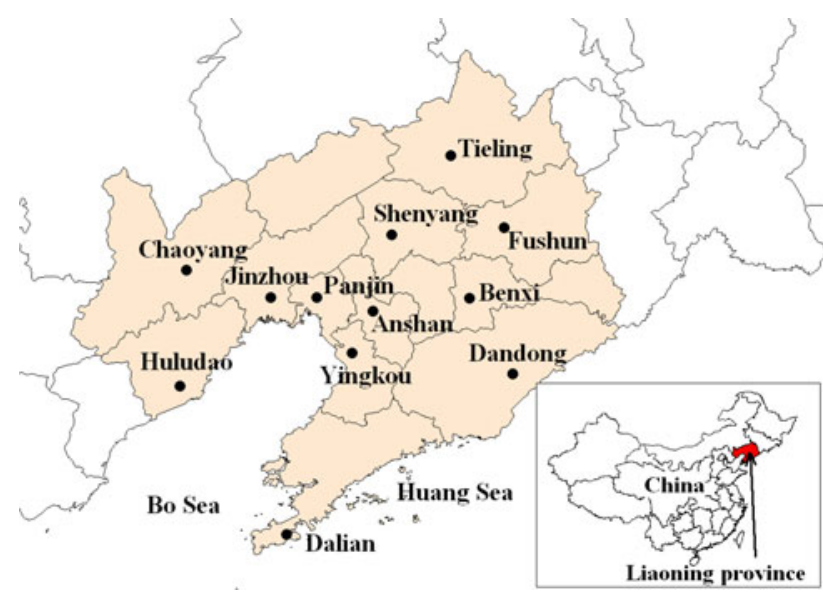

Fig. 1 Location of sampling sites four marine mollusks [oyster (Crassostrea gigas), mussel (Mytilus edulis), clam (Ruditapes philippinarum), and scallop (Chlamys farreri)]. For fish samples, one individual was treated as one sample, and for mollusk samples, three individuals were treated as one sample. So the final quantities of samples for marine fish, freshwater fish, and mollusks were 111, 148, and 148, respectively. Information on samples, by species, including numbers, length/height, ages, habitat use, and feeding ecology, are given in Table 1.

\section{Extraction and Analysis}

Five grams of homogenized sample and $10 \mathrm{~g}$ of anhydrous sodium sulfate were accurately measured into a precleaned extraction thimble, spiked with a surrogate standard mixture of CB155 and $\mathrm{D}_{8}-p, p^{\prime}$-DDT (purchased from Supelco, USA). After sufficient mixture, the samples were then Soxhlet extracted for $18 \mathrm{~h}$ with $200 \mathrm{ml}$ mixed solvent (hexane/acetone, 1:1, v/v). Ten percent of the extracts were used to determine lipid content gravimetrically (results according to species are given in Table 1); the remaining extracts $(90 \%)$ were bathed three times using $98 \% \mathrm{H}_{2} \mathrm{SO}_{4}$ and rotary-evaporated to $1 \mathrm{ml}$. Extracts were passed through a 5.5-g silica gel column (Silica 60; Merck, Germany), after prerinse with $25 \mathrm{ml}$ of hexane, eluted with $25 \mathrm{ml}$ of hexane for PCBs, HCB, and aldrin, and $50 \mathrm{ml}$ of a hexane/dichloromethane mixture $(1: 1, \mathrm{v} / \mathrm{v})$ for other OCPs. Elutions were rotary-evaporated to $2 \mathrm{ml}$ and then reduced to $1 \mathrm{ml}$ under a gentler nitrogen gas flow. All OCPs were quantified with GC-ECD (Agilent 6820). DB-5 MS of $0.25-\mathrm{mm}$ ID and $30-\mathrm{m}$ length was used for analysis of OCPs. The column oven temperature was programmed at an increasing rate of $15 \% \mathrm{~min}$ from an initial temperature of $80^{\circ} \mathrm{C}$ to a temperature of $160^{\circ} \mathrm{C}$ and then, at a rate of $3 \%$ min, to $280^{\circ} \mathrm{C}$ (5-min hold). Injector and ECD temperatures were 250 and $300^{\circ} \mathrm{C}$, respectively.

\section{Quality Assurance/Quality Control}

A mixture of $22 \mathrm{OCP}$ standards, including $\alpha-\mathrm{HCH}, \beta-\mathrm{HCH}$, $\gamma$-HCH, $\delta$-HCH, HCB, $p, p^{\prime}$-DDT, $o, p^{\prime}$-DDT, $p, p^{\prime}$-DDE, $o, p^{\prime}$-DDE, $p, p^{\prime}$-DDD, $o, p^{\prime}$-DDD, cis-chlordane (CC), transchlordane (TC), trans-nonachlor (TN), $\alpha$-endosulfan, $\beta$-endosulfan, endosulfan sulfate, heptachlor, heptachlor epoxide (isomer $\beta$ ), aldrin, endrin, and dieldrin, was purchased from Supelco, Inc. (USA).

All samples were spiked with a labeled recovery standard containing CB155 and $\mathrm{D}_{8}-p, p^{\prime}$-DDT prior to extraction. The surrogate standards of CB155 and $\mathrm{D}_{8}-p, p^{\prime}$-DDT recoveries were $89 \pm 18$ and $105 \pm 16$, respectively. Spike and blank samples were included at a rate of 1 for every 10 samples extracted, and the average spike 
Table 1 Information on fish and mollusk samples

\begin{tabular}{|c|c|c|c|c|c|c|c|}
\hline Species & Scientific name & No. & $\begin{array}{l}\text { Length/ } \\
\text { height }^{\mathrm{a}}\end{array}$ & Age & $\begin{array}{l}\text { Lipid } \\
\text { content }(\%)\end{array}$ & Habitat & Feeding \\
\hline \multicolumn{8}{|l|}{ Marine fish } \\
\hline Hairtail & Trichiurus haumela & 37 & $65 \pm 18$ & $3-4$ & $2.15 \pm 1.07$ & Ocean, offshore & Carnivore, little fish \\
\hline Small yellow croaker & Psendosciaena polyactis & 37 & $12 \pm 4$ & $2-3$ & $1.87 \pm 0.92$ & Ocean, offshore & Omnivore, little fish, \& shrimp \\
\hline Spanish mackerel & Scomberomorus niphonius & 37 & $31 \pm 6$ & $2-4$ & $2.00 \pm 1.00$ & Ocean, offshore & Carnivore, little fish \\
\hline \multicolumn{8}{|l|}{ Freshwater fish } \\
\hline Bighead carp & Aristichthys nobilis & 37 & $45 \pm 10$ & $3-5$ & $1.62 \pm 0.86$ & Pool, lake, \& river & Filter-feeding, plankton \\
\hline Common carp & Cyprinus carpio & 37 & $35 \pm 8$ & $2-4$ & $1.92 \pm 0.97$ & Pool, lake, \& river & Omnivore, zoobenthos \\
\hline Silver carp & Hypophthalmichthys molitrix & 37 & $41 \pm 7$ & $3-4$ & $1.94 \pm 1.05$ & Pool, lake, \& river & Filter-feeding, plankton \\
\hline Crucian carp & Carassius auratus & 37 & $21 \pm 5$ & $2-3$ & $2.09 \pm 1.16$ & Pool, lake, \& river & $\begin{array}{l}\text { Omnivore, organic detritus, } \\
\& \text { zoobenthos }\end{array}$ \\
\hline \multicolumn{8}{|l|}{ Marine mollusks } \\
\hline Oyster & Crassostrea gigas & 111 & $5.3 \pm 2.1$ & $3-5$ & $1.64 \pm 0.71$ & Tideland & Filter-feeding, unicellular algae \\
\hline Mussel & Mytilus edulis & 111 & $3.1 \pm 1.4$ & $2-3$ & $1.76 \pm 0.79$ & Bottom-dwelling & Filter-feeding, unicellular algae \\
\hline Clam & Ruditapes philippinarum & 111 & $4.5 \pm 2.3$ & $2-3$ & $1.58 \pm 0.79$ & Bottom-dwelling & Filter-feeding, unicellular algae \\
\hline Scallop & Chlamys farreri & 111 & $6.3 \pm 3.2$ & $2-3$ & $1.65 \pm 0.77$ & Bottom-dwelling & Filter-feeding, unicellular algae \\
\hline
\end{tabular}

a Length is used here for fish samples; it is from the front of the head to the end of the tail. Height is used for mollusk samples; it is from the center of opening sites to the closed end

recoveries fell in the range of $75-98 \%$, except for $p, p^{\prime}-$ DDE (63\%). The instrument detection limits (IDLs) were determined by assessing the injection amount that corresponded to a signal-to-noise ratio of 3:1. For $\alpha-\mathrm{HCH}$, $\beta$ - $\mathrm{HCH}, \gamma-\mathrm{HCH}, \delta$ - $\mathrm{HCH}, \mathrm{HCB}$, aldrin, $\mathrm{CC}, \mathrm{TC}, \alpha$-endosulfan, trans-nonachlor, and $p, p^{\prime}$-DDE, IDL values were $1 \mathrm{pg}$, and the values for other OCPs reached $5 \mathrm{pg}$. Results are reported only if the signal exceeded three times the baseline noise. All blanks were below the IDL.

\section{Results and Discussion}

\section{Analysis of General Contamination}

Preliminary analysis indicated that DDT (sum of $p, p^{\prime}$-DDT, $o, p^{\prime}$-DDT, $p, p^{\prime}$-DDE, $o, p^{\prime}$-DDE, $p, p^{\prime}$-DDD, and $o, p^{\prime}$-DDD), $\mathrm{HCH}$ (sum of $\alpha-\mathrm{HCH}, \beta-\mathrm{HCH}, \gamma-\mathrm{HCH}$, and $\delta-\mathrm{HCH}$ ), endosulfan (sum of $\alpha$-endosulfan, $\beta$-endosulfan, and endosulfan sulfate), chlordane (sum of cis-chlordane, transchlordane, and trans-nonachlor), and HCB were the predominant and ubiquitous OCPs residues in the fish and mollusk samples. The mean concentrations, concentration ranges, and occurrences of these organochlorine pesticides by species are listed in Table 2 . In all samples (including fish and mollusks), DDT concentrations ranged from 0.57 to $177.56 \mathrm{ng} / \mathrm{g}$ [all normalized to wet weight (ww) except where indicated], and occurrence frequencies were $100 \%$. The concentration ranges and occurrence frequencies, respectively, of $\mathrm{HCH}$, endosulfan, chlordane, and $\mathrm{HCB}$ were BDL (below detection limit) to $22.99 \mathrm{ng} / \mathrm{g}$ and $95 \%$, BDL to
$13.1 \mathrm{ng} / \mathrm{g}$ and $67 \%$, BDL to $15.68 \mathrm{ng} / \mathrm{g}$ and $40 \%$, and BDL to $9.21 \mathrm{ng} / \mathrm{g}$ and $53 \%$, respectively; details are discussed in the following. For other OCPs, such as heptachlor, heptachlor epoxide, aldrin, endrin, and dieldrin, the occurrence frequencies were $5,11,4,3$, and $3 \%$ (Table 3), respectively; this is not discussed further here, because only a small portion of the samples was analyzed. The residue levels of these seldom detected OCPs are also listed in Table 3.

Analysis of OCP Concentrations

\section{$D D T$}

DDT showed the highest concentration of all OCPs analyzed. Concentrations of DDT were 1-2 orders of magnitude higher than those of $\mathrm{HCH}$, endosulfan, chlordane, and HCB. Higher concentrations of DDT in fish and mollusks have also been reported by other groups (Nakata et al. 2002; Yang et al. 2006; Guo et al. 2007; Wang et al. 2007) in other regions of China, which indicates that these pollutants are ubiquitous in the biosphere of China. Two possible reasons for the higher DDT concentrations in the study area are the heavy historical usage and the existence of a potential new source. DDT was in widespread use in China from the $1950 \mathrm{~s}$ to 1983 (Li et al. 1999), and a recent study reported that DDT is still being produced in China for use in malaria control and is also present as an impurity in dicofol, an insecticide currently used in China (Qiu et al. 2005). The mean concentration of DDT in all fish samples was $18.75 \mathrm{ng} / \mathrm{g}$ in this study, higher than the $6 \mathrm{ng} / \mathrm{g}$ reported by Meng et al. for Guangdong province, China (2007). The 
Table 2 Concentrations [mean \pm SD (range) $\mathrm{ng} / \mathrm{g}$, ww] and occurrences $(n=)$ of major detected organochlorine pesticides in fish and mollusk species in 12 cities in Liaoning province

\begin{tabular}{|c|c|c|c|c|c|c|c|c|c|c|c|c|}
\hline \multirow{2}{*}{$\begin{array}{l}\text { Species } \\
\text { Hairtail }\end{array}$} & \multirow{2}{*}{$\frac{p, p^{\prime} \text {-DDT }}{3.51 \pm 3.38}$} & $o, p^{\prime}$-DDT & $p, p^{\prime}-\mathrm{DDE}$ & $o, p^{\prime}-\mathrm{DDE}$ & \multicolumn{2}{|c|}{$p, p^{\prime}-\mathrm{DDD}$} & \multicolumn{2}{|c|}{$o, p^{\prime}-\mathrm{DDD}$} & \multicolumn{2}{|l|}{$\alpha-\mathrm{HCH}$} & $\beta$-HCH & $\gamma-\mathrm{HCH}$ \\
\hline & & $3.94 \pm 5.59$ & $4.96 \pm 10.19$ & $3.91 \pm 10.92$ & \multirow{2}{*}{\multicolumn{2}{|c|}{$\begin{array}{l}3.38 \pm 10.68 \\
(B D L-65.65)\end{array}$}} & \multirow{2}{*}{\multicolumn{2}{|c|}{$\begin{array}{l}2.52 \pm 2.72 \\
(B D L-10.56)\end{array}$}} & \multirow{2}{*}{\multicolumn{2}{|c|}{$\begin{array}{l}0.09 \pm 0.09 \\
(B D L-0.43)\end{array}$}} & $0.26 \pm 0.21$ & $0.09 \pm 0.10$ \\
\hline \multirow{2}{*}{ Hairtail } & (BDL-11.4) & (BDL-32.11) & (BDL-60.6) & (BDL-65.2) & & & & & & & (BDL-0.99) & $(\mathrm{BDL}-0.51)$ \\
\hline & $n=36$ & $n=36$ & $n=33$ & $n=36$ & \multicolumn{2}{|c|}{$n=35$} & \multicolumn{2}{|c|}{$n=32$} & \multicolumn{2}{|l|}{$n=32$} & $n=35$ & $n=30$ \\
\hline \multirow[t]{3}{*}{ Small yellow croaker } & $3.52 \pm 2.98$ & $4.06 \pm 8.84$ & $5.70 \pm 32.65$ & $3.01 \pm 6.53$ & 3.8 & \pm 8.40 & 4.94 & $\llcorner 13.63$ & $1.05 \pm$ & & $0.21 \pm 0.16$ & $0.13 \pm 0.21$ \\
\hline & $(0.24-9.79)$ & (BDL-54.99) & (BDL-128.26) & $(\mathrm{BDL}-40.00)$ & $(\mathrm{BD}$ & $-51.5)$ & (BDI & 60.54) & (BDL-6 & & $(\mathrm{BDL}-0.65)$ & (BDL-1.04) \\
\hline & $n=37$ & $n=36$ & $n=34$ & $n=35$ & $n=$ & & $n=$ & & $n=30$ & & $n=34$ & $n=28$ \\
\hline Spanish mackerel & $4.31 \pm 12.94$ & $2.79 \pm 1.89$ & $6.94 \pm 11.23$ & $2.99 \pm 8.82$ & 2.44 & \pm 6.55 & 3.99 & \& 12.69 & $1.03 \pm 2$ & & $0.28 \pm 0.34$ & $0.11 \pm 0.27$ \\
\hline & $(0.07-80.29)$ & $(0.13-9.43)$ & $(\mathrm{BDL}-51.2)$ & (BDL-54.10) & (BD & $-39.86)$ & (BD & 76.77) & (BDL-1 & & (BDL-1.82) & (BDL-1.64) \\
\hline & $n=37$ & $n=37$ & $n=35$ & $n=35$ & $n=$ & & $n=$ & & $n=31$ & & $n=35$ & $n=30$ \\
\hline Bighead carp & $6.17 \pm 19.89$ & $5.07 \pm 7.27$ & $9.29 \pm 22.04$ & $4.86 \pm 7.21$ & 3.02 & \pm 3.13 & 5.81 & $\neq 13.57$ & $0.30 \pm($ & & $0.59 \pm 0.80$ & $0.22 \pm 0.25$ \\
\hline & (BDL-111.83) & $(0.09-35.5)$ & (BDL-98.7) & $(\mathrm{BDL}-39.86)$ & (BD & $-12.94)$ & (BI & $65.65)$ & $(\mathrm{BDL}-$ & & $(\mathrm{BDL}-4.01)$ & $(\mathrm{BDL}-1.03)$ \\
\hline & $n=36$ & $n=37$ & $n=34$ & $n=34$ & $n=$ & & $n=$ & & $n=29$ & & $n=32$ & $n=30$ \\
\hline Common carp & $7.22 \pm 21.75$ & $5.82 \pm 12.23$ & $8.68 \pm 18.72$ & $5.51 \pm 11.82$ & 4.50 & \pm 7.34 & 5.2 & 9.37 & $0.29 \pm$ & & $0.45 \pm 0.42$ & $0.22 \pm 0.22$ \\
\hline & (BDL-98.04) & $(0.41-54.99)$ & (BDL-98.7) & (BDL-67.5) & $(\mathrm{BD}$ & $-45)$ & (BDI & $-51.5)$ & (BDL-2 & & (BDL-2.14) & (BDL-0.90) \\
\hline & $n=36$ & $n=37$ & $n=33$ & $n=34$ & $n=$ & & $n=$ & & $n=34$ & & $n=33$ & $n=33$ \\
\hline Silver carp & $4.67 \pm 12.83$ & $4.28 \pm 3.65$ & $8.71 \pm 13.84$ & $5.10 \pm 10.20$ & 4.94 & \pm 8.13 & 4. & $\leq 7.71$ & $0.34 \pm$ & & $0.43 \pm 0.53$ & $0.29 \pm 0.43$ \\
\hline & (BDL-78.34) & $(0.13-18.41)$ & (BDL-55.44) & (BDL-50.09) & $(\mathrm{BD}$ & $-43.43)$ & (BDI & $-43.4)$ & (BDL-4 & & (BDL-3.01) & (BDL-2.09) \\
\hline & $n=36$ & $n=37$ & $n=33$ & $n=35$ & $n=$ & & $n=$ & & $n=30$ & & $n=32$ & $n=32$ \\
\hline Crucian carp & $3.76 \pm 9.13$ & $5.87 \pm 11.38$ & $7.97 \pm 20.43$ & $5.18 \pm 12.25$ & 4.67 & \pm 10.88 & 5.61 & t 12.12 & $0.55 \pm$ & & $0.73 \pm 1.20$ & $0.31 \pm 0.89$ \\
\hline & (BDL-56.43) & $(0.23-54.1)$ & (BDL-90.76) & (BDL-55.44) & $(\mathrm{BD}$ & $-66.61)$ & (BD & $-54.4)$ & (BDL-5 & & (BDL-6.76) & (BDL-5.41) \\
\hline & $n=36$ & $n=37$ & $n=33$ & $n=34$ & $n=$ & & $n=$ & & $n=29$ & & $n=31$ & $n=33$ \\
\hline Oyster & $2.63 \pm 2.90$ & $2.54 \pm 3.83$ & $1.92 \pm 2.47$ & $2.92 \pm 7.38$ & 1.82 & \pm 2.32 & 1.94 & \pm 2.40 & $0.13 \pm$ & & $0.16 \pm 0.19$ & $0.13 \pm 0.17$ \\
\hline & $(0.15-10.31)$ & (BDL-21.21) & (BDL-10.41) & $(\mathrm{BDL}-40.81)$ & (BD & $-10.75)$ & (B) & 10.75) & (BDL- & & (BDL-0.88) & (BDL-0.92) \\
\hline & $n=37$ & $n=36$ & $n=32$ & $n=33$ & $n=$ & & $n=$ & & $n=29$ & & $n=28$ & $n=33$ \\
\hline Mussel & $2.90 \pm 2.08$ & $1.63 \pm 1.78$ & $2.72 \pm 6.83$ & $1.70 \pm 1.96$ & 2.03 & \pm 3.89 & 2.64 & 4.08 & $0.12 \pm$ & & $0.21 \pm 0.19$ & $0.08 \pm 0.14$ \\
\hline & $(0.38-9.01)$ & $(0.03-5.67)$ & (BDL-41.4) & (BDL-5.67) & (BD & $-23.01)$ & (BDI & $-23.01)$ & (BDL-0 & & (BDL-0.68) & (BDL-0.54) \\
\hline & $n=37$ & $n=37$ & $n=32$ & $n=33$ & $n=$ & & $n=$ & & $n=28$ & & $n=29$ & $n=27$ \\
\hline Clam & $2.18 \pm 1.81$ & $2.54 \pm 2.57$ & $3.35 \pm 4.43$ & $1.86 \pm 2.21$ & 2.15 & \pm 2.41 & 2.28 & 2.58 & $0.15 \pm$ & & $0.26 \pm 0.31$ & $0.10 \pm 0.10$ \\
\hline & $(0.11-7.98)$ & (BDL-10.56) & (BDL-20.12) & (BDL-6.56) & $(\mathrm{BD}$ & -9.41) & (BDI & $-9.79)$ & (BDL-0 & & $(\mathrm{BDL}-1.10)$ & (BDL-0.32) \\
\hline & $n=37$ & $n=32$ & $n=32$ & $n=33$ & $n=$ & & $n=$ & & $n=30$ & & $n=28$ & $n=29$ \\
\hline Scallop & $2.89 \pm 3.86$ & $1.59 \pm 1.78$ & $2.68 \pm 3.78$ & $1.07 \pm 1.28$ & 1.41 & \pm 1.66 & 1.74 & 上 1.84 & $0.11 \pm$ & & $0.20 \pm 0.23$ & $0.08 \pm 0.10$ \\
\hline & $(0.15-21.2)$ & (BDL-7.65) & (BDL-18.41) & (BDL-4.56) & (BD & $-7.65)$ & (BI & $6.5)$ & $(\mathrm{BDL}-$ & & (BDL-0.99) & (BDL-0.4) \\
\hline & $n=37$ & $n=34$ & $n=33$ & $n=28$ & $n=$ & & $n=$ & & $n=24$ & & $n=28$ & $n=29$ \\
\hline Species & $\delta$-HCH & $\alpha$-Endosulfan & $\beta$-Endosulfan & Endosulfan $\mathrm{s}$ & te & cis-Ch & lane & trans $-\mathrm{C}$ & hlordane & tran & $\imath s$-Nonachlor & HCB \\
\hline Hairtail & $0.11 \pm 0.20$ & $0.80 \pm 1.63$ & $0.25 \pm 0.51$ & $0.14 \pm 0.42$ & & $0.73=$ & & $0.37=$ & 0.62 & 0 & \pm 0.60 & $0.40 \pm 0.95$ \\
\hline & $(\mathrm{BDL}-0.81)$ & (BDL-6.41) & (BDL-2.07) & $(\mathrm{BDL}-2.10)$ & & $(\mathrm{BDL}-$ & & (BDL-3 & & (B) & $(L-3.32)$ & (BDL-4.14) \\
\hline & $n=22$ & $n=17$ & $n=14$ & $n=7$ & & $n=25$ & & $n=19$ & & $n=$ & $=14$ & $n=18$ \\
\hline Small yellow croaker & $0.09 \pm 0.17$ & $0.61 \pm 1.70$ & $0.36 \pm 1.26$ & $0.20 \pm 0.54$ & & $0.40 \pm$ & & $0.22 \pm$ & 0.39 & $0.1 \mathrm{c}$ & $9 \pm 0.36$ & $0.40 \pm 0.77$ \\
\hline & (BDL-0.99) & (BDL-9.87) & (BDL-6.50) & $(\mathrm{BDL}-2.10)$ & & $(\mathrm{BDL}-4$ & & (BDL-1 & 35) & $(\mathrm{BD}$ & $\mathrm{L}-1.35)$ & (BDL-3.19) \\
\hline & $n=26$ & $n=15$ & $n=7$ & $n=6$ & & $n=15$ & & $n=12$ & & $n=$ & 10 & $n=16$ \\
\hline Spanish mackerel & $0.14 \pm 0.23$ & $0.93 \pm 1.48$ & $0.22 \pm 0.56$ & $0.01 \pm 0.04$ & & $0.44 \pm 0$ & & $0.32 \pm$ & 0.65 & 0.28 & $8 \pm 0.62$ & $0.58 \pm 1.09$ \\
\hline & $(\mathrm{BDL}-1.12)$ & (BDL-6.41) & (BDL-2.97) & $(\mathrm{BDL}-0.21)$ & & $(\mathrm{BDL}-$ & & (BDL-3 & & $(\mathrm{BD}$ & $\mathrm{L}-3.40)$ & (BDL-4.34) \\
\hline & $n=29$ & $n=24$ & $n=13$ & $n=3$ & & $n=16$ & & $n=14$ & & $n=$ & $=13$ & $n=22$ \\
\hline Bighead carp & $0.21 \pm 0.29$ & $1.94 \pm 2.91$ & $0.26 \pm 0.98$ & $0.15 \pm 0.69$ & & $0.39 \pm$ & & $0.25 \pm$ & 0.66 & & $7 \pm 0.28$ & $1.37 \pm 2.15$ \\
\hline & (BDL-1.03) & (BDL-10.31) & (BDL-5.65) & $(\mathrm{BDL}-4.12)$ & & $(\mathrm{BDL}-$ & & (BDL & & & $\mathrm{L}-1.39)$ & (BDL-9.21) \\
\hline & $n=27$ & $n=22$ & $n=6$ & $n=4$ & & $n=10$ & & $n=7$ & & $n=$ & $=3$ & $n=23$ \\
\hline Common carp & $0.10 \pm 0.22$ & $0.93 \pm 2.25$ & $0.48 \pm 1.07$ & $0.01 \pm 0.04$ & & $1.02 \pm$ & & $0.75 \pm$ & 1.50 & 0.30 & $0 \pm 0.76$ & $0.47 \pm 1.36$ \\
\hline & (BDL-1.01) & (BDL-10.08) & (BDL-5.43) & $(\mathrm{BDL}-0.21)$ & & (BDL- & 41) & (BDL-5 & 30) & & $\mathrm{L}-4.08)$ & (BDL-6.41) \\
\hline & $n=23$ & $n=16$ & $n=12$ & $n=5$ & & $n=14$ & & $n=13$ & & $n=$ & $=8$ & $n=14$ \\
\hline
\end{tabular}


Table 2 continued

\begin{tabular}{lllllllll}
\hline Species & $\delta$-HCH & $\alpha$-Endosulfan & $\beta$-Endosulfan & Endosulfan sulfate & cis-Chlordane & trans-Chlordane & trans-Nonachlor & HCB \\
\hline Silver carp & $0.11 \pm 0.21$ & $0.76 \pm 1.96$ & $0.34 \pm 0.84$ & $0.14 \pm 0.59$ & $0.64 \pm 1.33$ & $0.68 \pm 1.42$ & $0.29 \pm 0.73$ & $0.44 \pm 0.95$ \\
& $($ BDL-1.01) & $(\mathrm{BDL}-10.09)$ & $(\mathrm{BDL}-4.50)$ & $(\mathrm{BDL}-3.56)$ & $(\mathrm{BDL}-4.56)$ & $(\mathrm{BDL}-4.57)$ & $(\mathrm{BDL}-3.05)$ & $(\mathrm{BDL}-4.24)$ \\
& $n=24$ & $n=16$ & $n=9$ & $n=7$ & $n=8$ & $n=9$ & $n=6$ & $n=16$ \\
Crucian carp & $0.29 \pm 0.89$ & $1.28 \pm 2.26$ & $0.38 \pm 1.26$ & $0.28 \pm 0.83$ & $0.48 \pm 1.04$ & $0.38 \pm 0.92$ & $0.26 \pm 0.63$ & $0.98 \pm 1.55$ \\
& $(\mathrm{BDL}-5.41)$ & $(\mathrm{BDL}-11.2)$ & $(\mathrm{BDL}-6.89)$ & $(\mathrm{BDL}-4.41)$ & $(\mathrm{BDL}-5.44)$ & $(\mathrm{BDL}-4.31)$ & $(\mathrm{BDL}-3.14)$ & $(\mathrm{BDL}-6.41)$ \\
& $n=30$ & $n=24$ & $n=9$ & $n=12$ & $n=13$ & $n=11$ & $n=10$ \\
Oyster & $0.13 \pm 0.17$ & $1.07 \pm 1.72$ & $0.23 \pm 0.66$ & $0.06 \pm 0.18$ & $0.62 \pm 1.33$ & $0.43 \pm 0.99$ & $0.19 \pm 0.38$ & $0.71 \pm 0.98$ \\
& $(\mathrm{BDL}-0.92)$ & $(\mathrm{BDL}-9.21)$ & $(\mathrm{BDL}-3.06)$ & $(\mathrm{BDL}-0.97)$ & $(\mathrm{BDL}-5.41)$ & $(\mathrm{BDL}-5.41)$ & $(\mathrm{BDL}-1.31)$ & $(\mathrm{BDL}-3.13)$ \\
& $n=33$ & $n=25$ & $n=10$ & $n=5$ & $n=16$ & $n=13$ & $n=10$ \\
Mussel & $0.08 \pm 0.14$ & $0.38 \pm 1.08$ & $0.12 \pm 0.39$ & $0.04 \pm 0.15$ & $0.39 \pm 1.07$ & $0.12 \pm 0.22$ & $0.13 \pm 0.27$ & $0.59 \pm 1.17$ \\
& $(\mathrm{BDL}-0.54)$ & $(\mathrm{BDL}-5.41)$ & $(\mathrm{BDL}-2.09)$ & $(\mathrm{BDL}-0.89)$ & $(\mathrm{BDL}-5.11)$ & $(\mathrm{BDL}-0.78)$ & $(\mathrm{BDL}-1.13)$ & $(\mathrm{BDL}-4.06)$ \\
& $n=27$ & $n=12$ & $n=6$ & $n=7$ & $n=14$ & $n=11$ & $n=11$ \\
Clam & $0.09 \pm 0.10$ & $0.44 \pm 0.72$ & $0.34 \pm 0.97$ & $0.21 \pm 0.70$ & $0.17 \pm 0.54$ & $0.15 \pm 0.39$ & $0.14 \pm 0.38$ & $0.54 \pm 0.83$ \\
& $(\mathrm{BDL}-0.32)$ & $(\mathrm{BDL}-2.35)$ & $(\mathrm{BDL}-4.35)$ & $(\mathrm{BDL}-3.08)$ & $(\mathrm{BDL}-3.12)$ & $(\mathrm{BDL}-2.09)$ & $(\mathrm{BDL}-1.98)$ & $(\mathrm{BDL}-2.56)$ \\
& $n=29$ & $n=17$ & $n=9$ & $n=6$ & $n=10$ & $n=10$ & $n=9$ \\
Scallop & $0.08 \pm 0.10$ & $0.64 \pm 1.07$ & $0.26 \pm 0.72$ & $0.24 \pm 0.67$ & $0.29 \pm 0.81$ & $0.17 \pm 0.45$ & $0.04 \pm 0.12$ & $0.51 \pm 0.92$ \\
& $(\mathrm{BDL}-0.40)$ & $(\mathrm{BDL}-4.00)$ & $(\mathrm{BDL}-3.21)$ & $(\mathrm{BDL}-2.67)$ & $(\mathrm{BDL}-4.13)$ & $(\mathrm{BDL}-2.11)$ & $(\mathrm{BDL}-0.56)$ & $(\mathrm{BDL}-4.00)$ \\
& $n=27$ & $n=19$ & $n=9$ & $n=7$ & $n=11$ & $n=9$ & $n=5$ & $n=19$
\end{tabular}

For each species, the total number of samples is 37

$w w$ wet weight

Table 3 Minor detected organochlorine pesticide residues and their occurrence in fish and mollusks

\begin{tabular}{|c|c|c|c|c|c|c|}
\hline \multirow[t]{2}{*}{ Compound } & \multicolumn{2}{|l|}{ Marine fish } & \multicolumn{2}{|c|}{ Fresh water fish } & \multicolumn{2}{|c|}{ Marine mollusk } \\
\hline & Range & Occurrence & Range & Occurrence & Range & Occurrence \\
\hline Heptachlor & BDL-1.28 & 3 & BDL-0.98 & 7 & BDL-0.76 & 8 \\
\hline Heptachlor epoxide & BDL-0.98 & 13 & BDL-0.91 & 17 & BDL-0.97 & 13 \\
\hline Aldrin & BDL-0.20 & 6 & BDL-0.91 & 5 & BDL-0.97 & 5 \\
\hline Endrin & BDL-0.34 & 2 & BDL-0.98 & 8 & BDL-0.11 & 1 \\
\hline Dieldrin & BDL-0.76 & 4 & BDL-0.19 & 5 & BDL-0.96 & 4 \\
\hline
\end{tabular}

Note: Total numbers of samples are 111, 148, and 148 for marine fish, freshwater fish, and marine mollusks, respectively

DDT concentrations in fish and mollusk samples ranged from 0.84 to $212.16 \mathrm{ng} / \mathrm{g}$ in Dalian, China (Yang et al. 2006), and from 0.5 to $220 \mathrm{ng} / \mathrm{g}$ in Xiamen, China (Klump et al. 2002); these values are comparable to our concentrations, which ranged from 0.57 to $177.56 \mathrm{ng} / \mathrm{g}$. DDT concentrations in fish from around the world have been reported (Kannan et al. 1995; Sapozhnikova et al. 2004; Yim et al. 2005; Darnerud et al. 2006). Generally, the median concentration of DDT (18.54 ng/g) in Liaoning province was lower than that in Vietnam $(26 \mathrm{ng} / \mathrm{g})$, Indonesia (28 ng/g), and Australia (22 ng/g) but higher than that in India (15 ng/g), Thailand (6.2 ng/g), Papua New Guinea (0.43 ng/g) Solomon Islands (4.8 ng/g), Korea (8.96 ng/g), Sweden (7.02 ng/g), and Salton Sea, USA (17.6 ng/g). It is known that DDT can be biodegraded to DDE under aerobic conditions and to DDD under anaerobic conditions, and a value of $\mathrm{DDT} /(\mathrm{DDE}+\mathrm{DDD})>1$ can be used as an indicator of possible new sources. In this study, the median value of DDT/(DDE + DDD) was 0.48 , and it was $>1$ in $26 \%$ of samples. The results suggest that DDT concentrations in fish and mollusks are mainly due to historical use, but point sources of DDT exist currently in the study areas.

\section{$\mathrm{HCH}$}

The $\mathrm{HCH}$ concentration ranged from BDL to $22.99 \mathrm{ng} / \mathrm{g}$ in all fish and mollusk samples in this study; this range is comparable to that reported in fish in Guangdong province (0.13-24.06 ng/g) (Meng et al. 2007) but wider than those reported in other areas of China, including Dalian (fish and mollusks, 0.15-4.25 ng/g), Tianjin (fish and mollusks, 0.35-0.54 ng/g), Shanghai (fish and mollusks, 0.044-2.64 ng/g) (Yang et al. 2006), and Zhoushan (fish, $<0.1 \mathrm{ng} / \mathrm{g}$ ) (Jiang et al. 2005). In the case of fish 
samples, the mean value $(1.02 \mathrm{ng} / \mathrm{g})$ in this study was similar to those in Sweden $(0.96 \mathrm{ng} / \mathrm{g}$ ) (Darnerud et al. 2006), Thailand (0.82 ng/g), Australia (0.34 ng/g), Indonesia (0.73 ng/g), Papua New Guinea $(0.57 \mathrm{ng} / \mathrm{g})$, the Solomon Islands (0.53 ng/g) (Kannan et al. 1995), and Korea $(0.94 \mathrm{ng} / \mathrm{g})$ (Yim et al. 2005) but lower than those in India (28 ng/g) and Vietnam (1.8 ng/g) (Kannan et al. 1995). Historically, the quantity of technical $\mathrm{HCH}$ used in China $(4500 \mathrm{kt})$ was much higher than that of DDT $(270 \mathrm{kt})(\mathrm{Li}$ et al. 1998, 1999, 2001), but according to the residue data, a much lower concentration of $\mathrm{HCH}$ was observed. There could be two reasons for this: first, $\mathrm{HCH}$ has a higher biodegradability and a lower lipophilicity than DDT (Guo et al. 2007); and second, DDT has been released to the environment since 1983 due to the use of dicifol and other purposes (Qiu et al. 2005).

\section{Chlordane}

As an insecticide, chlordane has been widely used in China for termite control (Zhao 2005). In this study, the occurrence frequencies of chlordane were $42 \%$ in fish, ranging from BDL to $15.68 \mathrm{ng} / \mathrm{g}$, with a mean concentration of $1.25 \mathrm{ng} / \mathrm{g}$, and $36 \%$ in mollusks, ranging from BDL to $10.82 \mathrm{ng} / \mathrm{g}$, with a mean concentration of $0.71 \mathrm{ng} / \mathrm{g}$. The mean concentration in mollusk was comparable to those reported in Dalian (0.82 ng/g) (Yang et al. 2006) and Fuzhou (0.96 ng/g) (Monirith et al. 2003) and lower than those in Zhenjiang (3.48 ng/g), Shanghai (3.74 ng/g), Xiamen (2.02 ng/g), and Shenzhen (1.43 ng/g) (Monirith et al. 2003). Compared to other countries, the mean concentration in fish $(1.25 \mathrm{ng} / \mathrm{g})$ was higher than that in Vietnam $(0.11 \mathrm{ng} / \mathrm{g})$, Papua New Guinea (0.37 ng/g), Indonesia (0.45 ng/g), Solomon Islands $(0.57 \mathrm{ng} / \mathrm{g})$, but lower than India $(2.4 \mathrm{ng} / \mathrm{g})$, Thailand (2.6 ng/g), and Australia (51 ng/g) (Kannan et al. 1995).

\section{$H C B$}

HCB was used principally as an intermediate to produce pentachlorophenol (PCP) and Na-PCP in closed systems (Hu et al. 2007). The occurrence frequencies of HCB were $53 \%$ in fish, ranging from BDL to $9.21 \mathrm{ng} / \mathrm{g}$, with a mean concentration of $1.66 \mathrm{ng} / \mathrm{g}$; these values were much higher than those in other regions of China reported by Monirith et al. (2003), and also higher than those in other countries reported by Kannan et al. (1995), but much lower than those in Australia [range, <0.01-60; mean, 4.2 ng/g (Kannan et al. 1995)].

\section{Endosulfan}

Technical endosulfan, which consists of $\alpha$ - and $\beta$-isomers, is one of the few cyclodiene pesticides that is still used extensively throughout the world to control a number of insects on crops. In the environment, the cyclic sulfite group of endosulfan can be oxidized to the corresponding sulfate (endosulfan sulfate) (Chandler et al. 1991; Guerin et al. 1992; Kathpal et al. 1997), which is persistent than its parents (Guerin 2001). In China, endosulfan is currently used as pesticide for cotton, wheat, tea, tobacco, and apple tree (Jia et al. 2009). As for all samples (include fish and mollusks), endosulfan concentrations varied from BDL to $13.1 \mathrm{ng} / \mathrm{g}$, with a mean value of $1.50 \mathrm{ng} / \mathrm{g}$, and the occurrence frequency was $67 \%$. Due to the rarity of reports on endosulfan in fish and mollusk, few comparable data are available. It was reported that the endosulfan concentration in seafood from Guangdong province, China, ranged from 0.04 to $1.89 \mathrm{ng} / \mathrm{g}$ (Guo et al. 2007), much lower than that in this study. According to the report by Jia et al. (2009), compared to Guangdong province, endosulfan was more comprehensively used in Liaoning province, due to the need for control of insects on cotton and apple; we conclude that the greater usage led to the higher concentrations in fish and mollusks in Liaoning province.

\section{Comparing OCPs in Different Fish and Mollusk Species}

Toxic chemicals released to the environment from point sources such as industrial and municipal discharges and from nonpoint sources such as agricultural runoff and atmospheric deposition have contaminated surface waters across China. Many chemical pollutants concentrate in fish and mollusks by accumulating in fatty tissues or selectively binding to fish muscle tissue. Even extremely low concentrations of bioaccumulative pollutants detected in water or bottom sediments may result in accumulation in fish and shellfish. Thus aquatic organisms are commonly used for environmental monitoring of pollutants such as heavy metals, OCPs, and polychlorinated biphenyls (PCBs). In the aquatic system, fish and mollusks are on different positions in the food chain, thus different fish and mollusk species may lead to different OCPs concentration. Figure 2 displays the mean concentration of OCPs in various fish and mollusk species, which were divided into three groups (I is marine fish, II is freshwater fish, and III is mollusks). In general, OCP concentrations were obviously higher in fish than in mollusks and higher in freshwater fish than in marine fish. These results indicate that OCP accumulation is greater in freshwater fish than in marine fish and mollusk. This probably reflects the impact of contaminant discharge from Liaoning province in northern China. Typically, seawater fish and mollusks are cultured in intertidal zones, small bays, and shallow seas, while freshwater fish are raised in ponds, lakes, reservoirs, and river channels, which are close to agricultural areas. Freshwater fish may be more easily influenced than seawater fish and mollusks are by OCP residues in agricultural areas. In 

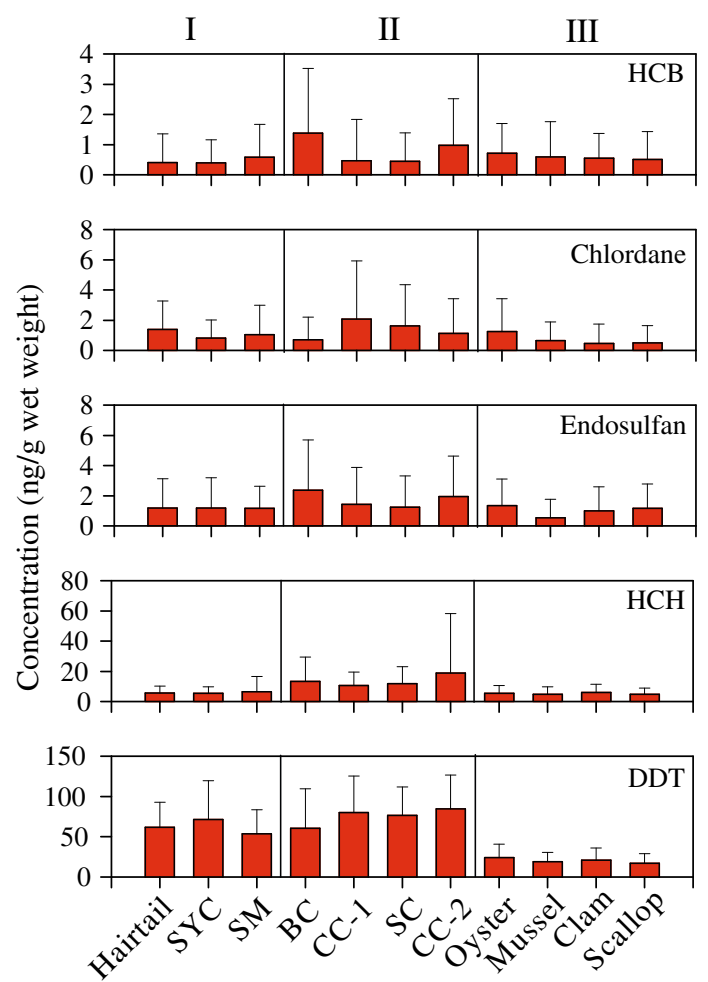

Species

Fig. 2 Average concentrations and standard deviations of DDT, $\mathrm{HCH}$, endosulfan, chlordane, and $\mathrm{HCB}$ in $(I)$ three marine fish, $(I I)$ four freshwater fish, and (III) four mollusks. SYC small yellow croaker, $S M$ Spanish mackerel, $B C$ bighead carp, $C C$ - 1 common carp, $S C$ silver carp, $C C$-2 crucian carp

addition, fish are at the top of the food chain in the aquatic system, so due to the biota accumulation feature of OCPs, fish suffer compound accumulation more easily than mollusks; our results reflect these characters.
Estimating Exposure

The analysis estimates exposure to specific contaminants via foods by combining data on contaminant concentrations in foods, which is commonly used to assess human risk. The acceptable daily intake (ADI) recommended by the Food and Agriculture Organization and World Health Organization (FAO/WHO) is usually used to assess human exposure to target contaminants, without consideration of different eating habits and consumption rates. To estimate individual exposure from fish and mollusks, we calculated the estimated daily intake (EDI; ng/kg body weight/day) of OCPs by the following equation:

$\mathrm{EDI}=\frac{\mathrm{FDC} \times \mathrm{CC}}{\mathrm{BW}}$

where FDC is food daily consumption, $\mathrm{CC}$ is the mean contaminant concentration of OCPs, and BW is body weight, for which $60 \mathrm{~kg}$ is typical (IPCS 2006).

To determine the consumption of fish and mollusk, 256 questionnaires were sent to the families in 12 cities of Liaoning province. The questionnaires included the information number of people, consumption frequencies and quantities consumed of these foods (researched in this paper), and data on consumption of other fish and mollusks. After statistical calculations, we got the general consumption information on these foods in Liaoning province, and the results are presented in Table 4. Amounts consumed ranged from 20.45 to $50.12 \mathrm{~g} /$ day, with a mean value of $34.08 \mathrm{~g} / \mathrm{day}$, for marine fish, from 23.45 to 40.35 $($ mean $=32.78) \mathrm{g} / \mathrm{day}$ for freshwater fish, and from 13.24 to 38.47 (mean $=24.12) \mathrm{ng} /$ day for mollusks. The consumption data arrived at are a little lower than the average consumption value of fishery food from the China Statistical Yearbook [38.90 g/day (NBSC 2008)].
Table 4 Consumptions (g/day) of fish and mollusk according to city in Liaoning province

Note: Percentages in parentheses are the market share of the species studied in this research

\begin{tabular}{lllll}
\hline City & $\begin{array}{l}\text { No. of } \\
\text { questionnaires }\end{array}$ & Marine fish & Freshwater fish & Mollusk \\
\hline Dalian & 21 & $48.33(70 \%)$ & $23.45(91 \%)$ & $29.25(75 \%)$ \\
Yingkou & 22 & $42.15(81 \%)$ & $30.12(89 \%)$ & $33.69(63 \%)$ \\
Dandong & 18 & $50.12(76 \%)$ & $32.15(93 \%)$ & $38.47(68 \%)$ \\
Anshan & 23 & $28.14(78 \%)$ & $30.12(83 \%)$ & $24.13(70 \%)$ \\
Panjin & 22 & $35.68(85 \%)$ & $25.46(93 \%)$ & $30.45(62 \%)$ \\
Benxi & 23 & $35.36(69 \%)$ & $36.15(85 \%)$ & $18.53(65 \%)$ \\
Fushun & 21 & $21.63(72 \%)$ & $34.66(87 \%)$ & $16.46(71 \%)$ \\
Shenyang & 22 & $30.87(80 \%)$ & $40.35(88 \%)$ & $15.11(67 \%)$ \\
Tieling & 18 & $20.45(65 \%)$ & $38.79(90 \%)$ & $14.21(58 \%)$ \\
Jinzhou & 21 & $38.43(70 \%)$ & $33.49(85 \%)$ & $25.78(57 \%)$ \\
Huludao & 22 & $33.46(75 \%)$ & $32.74(81 \%)$ & $30.12(75 \%)$ \\
Chaoyang & 23 & $24.31(73 \%)$ & $35.89(93 \%)$ & $13.24(56 \%)$ \\
\hline
\end{tabular}


Table 5 Human exposures and benchmark concentrations for contaminants in fish and mollusk

\begin{tabular}{llllc}
\hline Compound & Species & $\begin{array}{l}\text { Estimated daily } \\
\text { intake (ng/kg body } \\
\text { weight/day) }\end{array}$ & $\begin{array}{l}\text { Noncancer benchmark } \\
\text { concentration }(\mathrm{ng} / \mathrm{kg} \\
\text { body weight/day) }\end{array}$ & $\begin{array}{l}\text { Cancer benchmark } \\
\text { concentration }(\mathrm{ng} / \mathrm{kg} \\
\text { body weight/day) }\end{array}$ \\
\hline HCH & Marine fish & 0.33 & 300 & 1354 \\
& Freshwater fish & 0.74 & 300 & 1408 \\
DDT & Marine mollusk & 0.21 & 300 & 1914 \\
& Marine fish & 14.79 & 500 & 5178 \\
& Freshwater fish & 18.64 & 500 & 5383 \\
Chlordane & Marine mollusk & 5.34 & 500 & 7316 \\
& Marine fish & 0.61 & 500 & 5030 \\
& Freshwater fish & 0.76 & 500 & 5230 \\
Endosulfan & Marine mollusk & 0.29 & 500 & 7107 \\
& Marine fish & 0.66 & 6000 & - \\
& Freshwater fish & 0.95 & 6000 & - \\
\multirow{5}{*}{ HCB } & Marine mollusk & 0.40 & 6000 & 1100 \\
& Marine fish & 0.26 & 800 & 1144 \\
& Freshwater fish & 0.45 & 800 & 1555 \\
\hline & Marine mollusk & 0.24 & 800 & \\
\hline
\end{tabular}

Using the data from the present study, we calculated average EDIs of OCPs via fish and mollusk consumption; OCP concentrations use the mean value of marine fish, freshwater fish, and mollusk samples. As reported in Table 5, DDT clearly had the highest EDI values and also the highest values of OCPs for human exposure. In general, it showed the highest level of human exposure to OCPs through freshwater fish consumption, followed by marine fish and marine mollusks. Potential public health risks from exposure to OCPs by fish and mollusk consumption were assessed using two benchmark concentrations. A benchmark concentration represents the daily concentration below which there is a high probability of no adverse health effect. This is different from a benchmark dose, which is a statistically derived value used in setting a reference dose for noncancer health effects. The first benchmark concentrations were U.S. Environmental Protection Agency (EPA) Reference Dose (RfD) values, which were used for noncarcinogenic effects. The second benchmark concentrations were carcinogenic effects, which were derived using U.S. EPA cancer slope factors and represent exposure concentrations at which lifetime cancer risk is 1 in 1 million (USEPA 2006). The benchmark concentration is an estimate, with an uncertainty spanning perhaps an order of magnitude, of the daily exposure of the human population that is likely to be without appreciable risk of deleterious effects during a lifetime (USEPA 1990). Different benchmark concentrations of OCPs are also reported in Table 5 . In this study, none of the EDI values for OCPs exceeded the benchmark concentration, which suggests that these aquatic foods are safe to consume based on their contributions to the EDI of organic contaminants. Despite the risk assessment results showing that it is safe, the potential health risk associated with consumption of these products cannot be neglected. The widespread distribution and higher concentrations of certain compounds deserve further monitoring efforts to ensure the long-term safety of consumers in association with consumption of these food.

To assess geographical exposure, human exposures were calculated based on cities by association with concentration and consumption data. According to the locations, we divided the 12 cities into inland (including Chaoyang, Anshan, Benxi, Fushun, Shenyang, and Tieling) and coastal (included Dalian, Yingkou, Dandong, Panjin, Jinzhou, and Huludao). In general, there was higher exposure to OCPs by consumption of freshwater fish in inland cities than in

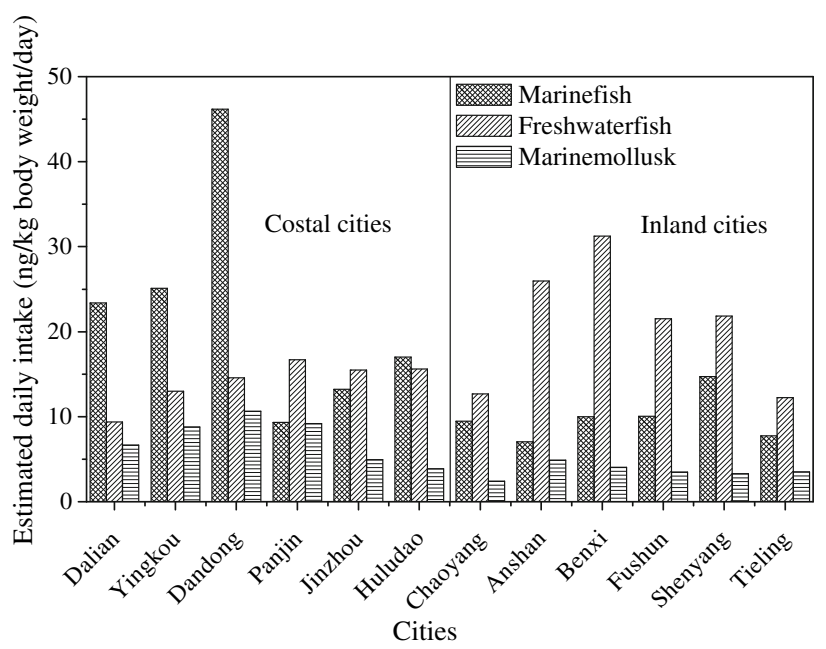

Fig. 3 Human exposure to DDT by consumption of fish and mollusks in different cities in Liaoning province 
costal cities, and the results were reversed for consumption of marine fish and mollusks (Fig. 3 presents the human exposure to DDT in 12 cities in Liaoning province), which reflects the different compositions of aquatic products consumed in different cities. We also calculated the total exposure of these foods, and one-way analysis (ANOVA) was used to assess the different exposure between coastal cities and inland cities; at the 0.05 level, there was no significant difference between them. The conclusion was that, in geographical terms, residents of both inland and coastal regions were subjected to the same total exposure to OCPs by consumption of fish and mollusks.

Some limitations associated with exposure analysis can lead to uncertainty in the total risk. For example, our risk analysis did not consider different ages, and childhood exposure may have a greater probability of producing tumors than exposure in adulthood. The use of mean fish and mollusk contaminant concentrations to estimate exposure is another limitation that could underestimate risk if an individual regularly consumes fish and mollusks from a contaminated water body. In addition, human body weight and possible interactions among different toxic chemicals could lead to uncertainties. Our study, however, provides a clear picture of the distribution of OCPs in fish and mollusks and a risk assessment of human exposure in Liaoning province, China.

Open Access This article is distributed under the terms of the Creative Commons Attribution Noncommercial License which permits any noncommercial use, distribution, and reproduction in any medium, provided the original author(s) and source are credited.

\section{References}

Chandler GT, Scott GI (1991) Effects of sediment-bound endosulfan on survival, reproduction and larval settlement of meiobenthic polychaetes and copepods. Environ Toxicol Chem 10:375383

Darnerud PO, Atuma S, Aune M, Bjerselius R, Glynn A, Grawe KP, Becher W (2006) Dietary intake estimations of organohalogen contaminants (dioxins, PCB, PBDE and chlorinated pesticides, e.g. DDT) based on Swedish market basket data. Food Chem Toxicol 44:1597-1606

Guerin TF (2001) Abiological loss of endosulfan and related chlorinated organic compounds from aqueous systems in the presence and absence of oxygen. Environ Pollut 115:219-230

Guerin TF, Kennedy IR (1992) Distribution and dissipation of endosulfan and related cyclodienes in sterile aqueous systems: implications for studies on biodegradation. J Agr Food Chem 40:2315-2323

Guo JY, Zeng EY, Wu FC, Meng XZ, Mai BX, Luo XJ (2007) Organochlorine pesticides in seafood products from southern China and health risk assessment. Environ Toxicol Chem 26: $1109-1115$

Hu JX, Zhu T, Li QL (2007) Organochlorine pesticides in China. In: Developments in environmental science, vol 7. Elsevier, New York, chap 3
International Programme on Chemical Safety (IPCS) (2006) Inventory of IPCS and other WHO pesticide evaluations and summary of toxicological evaluations performed by the joint meeting on pesticide residues (JMPR) through 2005. Available at: http://www.who.int/ ipcs/publications/jmpr/jmpr_pesticide/en/index.html. Accessed November 2006

Jia HL, Li YF, Wang DG, Cai DJ, Yang M, Ma JM, Hu JX (2009) Endosulfan in China 1-gridded usage inventories. Environ Sci Pollut Res 16:295-301

Jiang QT, Lee TK, Chen K, Wong HL, Zheng JS, Giesy JP, Lo KK, Yamashita N, Lam PK (2005) Human health risk assessment of organochlorines associated with fish consumption in a coastal city in China. Environ Pollut 136:155-165

Kannan K, Tanabe S, Tatsukawa R (1995) Geographical distribution and accumulation features of organochlorine residues in fish in tropical Asia and Oceania. Environ Sci Technol 29:2673-2683

Kathpal TS, Singh A, Dhankar JS, Singh G (1997) Fate of endosulfan in cotton soil under sub-tropical conditions of northern India. Pestic Sci 50:21-27

Klump DW, Hong HS, Humphrey C, Wang XH, Codi S (2002) Toxic contaminants and their biological effects in coastal waters of Xiamen, China. I. Organic pollutants in mussel and fish tissues. Mar Pollut Bull 44:752-760

Li YF, Cai DJ, Singh A (1998) Technical hexachlorocyclohexane use trends in China and their impact on the environment. Arch Environ Contam Toxicol 35:688-697

Li YF, Cai DJ, Singh A (1999) Historical DDT use trends in China and usage data gridding with $1 / 4^{\circ}$ by $1 / 6^{\circ}$ longitude/latitude resolution. Adv Environ Res 2:497-506

Li YF, Cai DJ, Shan ZJ, Zhu ZL (2001) Gridded usage inventories of technical hexachlorocyclohexane and lindane for China with $1 /$ $6^{\circ}$ latitude by $1 / 4^{\circ}$ longitude resolution. Arch Environ Contam Toxicol 41:261-266

MacIntosh DL, Spengler JD, Ozkaynak H, Tsai L, Ryan PB (1996) Dietary exposures to selected metals and pesticides. Environ Health Persp 104:202-209

Meng XZ, Zeng EY, Yu LP, Mai BX, Luo XJ, Ran Y (2007) Persistent halogenated hydrocarbons in consumer fish of China: regional and global implications for human exposure. Environ Sci Technol 41:1821-1827

Monirith I, Ueno D, Takahashi S, Nakata H et al (2003) Asia-Pacific mussel watch: monitoring contamination of persistent organochlorine compounds in coastal waters of Asian countries. Mar Pollut Bull 46:281-300

Nakata H, Kawazoe M, Arizono K, Abe S, Kitano T, Shimada H, Li W, Ding X (2002) Organochlorine pesticides and polychlorinated biphenyl residues in foodstuffs and human tissues from China: status of contamination, historical trend, and human dietary exposure. Arch Environ Contam Toxicol 43:473-480

National Bureau of Statistics of China (NBSC) (2008) China statistical yearbook, 2008. Available at: www.stats.gov.cn/tjsj/ ndsj/2008/indexch.htm. Accessed September 2008

National Research Council (NRC) (1993) Pesticides in the diets of infants and children. National Academic Science Research Council, Washington, DC

Qiu X, Zhu T, Yao B, Hu J, Hu S (2005) Contribution of dicofol to the current DDT pollution in China. Environ Sci Technol 39:4385-4390

Sapozhnikova Y, Bawardi O, Schlenk D (2004) Pesticides and PCBs in sediments and fish from Salton Sea, California, USA. Chemosphere 55:797-809

U.S. Environmental Protection Agency (USEPA) (1990) Interim methods for development of inhalation reference concentrations. Office of Research and Development, U.S. EPA, Washington, DC

U.S. Environmental Protection Agency (USEPA) (2006) Guidance for assessing chemical contaminant data for use in fish 
advisories. Vol. 2: Risk assessment and fish consumption limits. Available at: http://www.epa.gov/ost/fishadvice/volum2/index. html. Accessed September 2006

Wang YW, Yang RQ, Jiang GB (2007) Investigation of organochlorine pesticides (OCPs) in mollusks collected from coastal sites along the Chinese Bohai Sea from 2002 to 2004. Environ Pollut 146:100-106

Wiles R, Davies K, Campbell C (1998) Overexposed: organophosphate insecticides in children's food. Environmental Working Group, Washington, DC
Yang NQ, Matsuda M, Kawano M, Wakimoto T (2006) PCBs and organochlorine pesticides (OCPs) in edible fish and shellfish from China. Chemosphere 63:1342-1352

Yim UH, Hong SH, Shim WJ, Oh JR (2005) Levels of persistent organochlorine contaminants in fish from Korea and their potential health risk. Arch Environ Contam Toxicol 48:358-366

Zhao LJ (2005) Usage inventories for selected persistent organic pollutants in China. Master's thesis, Peking University, Beijing 